\title{
AUDIT TATA KELOLA TEKNOLOGI INFORMASI PADA PERGURUAN TINGGI SWASTA DI SURAKARTA (Studi Kasus: Politeknik Indonusa Surakarta)
}

\author{
Slamet Aldian \\ 1611050146 \\ Fakultas Ilmu Komputer \\ Jurusan Sistem Informasi \\ Slametaldian02225@gmail.com
}

\begin{abstract}
Abstrak
Their IT governance in higher education can provide one support to determine the benefits and risks that would be obtained. Audit of information technology governance in Politeknik Indonusa Surakarta conducted to assess, ascertain, find out what the cause and provide recommendations on the application of information technology in polytechnics indonusa Surakarta. To evaluate an information technology must use a tool such as the framework and framework used is COBIT 5, because the problem is also related to the management area contained in the framework.

In this research for problem resolution will refer to the Standard Framework COBIT 5 with Of Enterprise IT Management of area and more focused on domain MEA (Monitor, Evaluate and Assess) on the control objective is MEAO1 - Monitor, Evaluate, and Assess Performance and Conformance. Scope of IT governance is SIAKAD (Sistem Informasi Akademik), SIMANTA (Sistem Informasi Manajemen Tugas Akhir).

The study provides, among others, the level of ability (Capability Level) the application of information technology today, obstacles in the implementation of IT, as well as provide recommendations can be given with regard to the use of IT.
\end{abstract}

\section{Keywords: Audit governance, COBIT 5, Domain MEA01}

\section{PENDAHULUAN}

a. Latar Belakang

Perkembangan Teknologi Informasi (TI) yang cepat memunculkan perangkat keras dan perangkat lunak dengan biaya murah. Perkembangan ini memunculkan berbagai macam aplikasi dan model pengelolaan terhadap TI. Berbagai perkembangan TI ini membuat banyak perusahaan mengalami pergeseran dari sistem manual ke komputerisasi sehingga penyimpanan data menjadi efesien, informasi yang up to date, dan cepat dalam penyajian informasi. (Abdi Darmawan dan Muhammad Said Hasibuan, 2014)

Pemanfaatan TI perlu adanya tata kelola yang cukup baik, menurut Ivan Martha Kurnia dan Fajrian Nur Adnan (2014) "Tata kelola TI adalah suatu struktur dan proses yang saling berhubungan serta mengarahkan dan mengendalikan perusahaan dalam pencapaian tujuan perusahaan melalui nilai tambah dan penyeimbangan antara risiko dan manfaat dari teknologi informasi serta prosesnya".

Politeknik Indonusa Surakarta telah mengimplementasikan beberapa Sistem Informasi antara lain SIPEMARU (Sistem Informasi Penerimaan Mahasiswa Baru), SIAKAD (Sistem Informasi Akademik), SIMPUS (Sistem Informasi Perpustakaan), SIMANTA (Sistem Informasi Manajemen Tugas Akhir), SINAPRA (Sistem Informasi Sarana dan Prasarana), SIKEU (Sistem Informasi Keuangan), SIMPEG (Sistem Informasi Kepegawaian), E-learning. Sistem informasi diatas diimplementasikan untuk membantu meningkatkan kinerja lembaga pendidikan tinggi serta memberikan layanan yang baik kepada para Mahasiswa. Untuk pengelolaan Sistem Informasi yang ada di Politeknik Indonusa Surakarta dibawah kendali UTI (Unit Teknologi Informasi). 
Penerapan Teknologi Informasi di Politeknik Indonusa Surakarta mengalami beberapa kendala antara lain:

1) UTI (Unit Teknologi Informasi) belum bisa melaksanakan kebijakan, prosedur, dan pengukuran teknis yang digunakan untuk mencegah akses yang tidak sah, perubahan program, pencurian data, atau kerusakan fisik terhadap sistem informasi.

2) Pembagian dan pemisahan tugas yang berperan dalam menciptakan pengawasan sistem keamanan yang baik untuk mengantisipasi tindak kecurangan dan penyalahgunaan dalam sistem keamanan teknologi informasi belum tertata.

3) Pelaksanaan ujicoba rutin yang dilakukan untuk mengevaluasi suatu kebijakan yang sudah diterapkan dalam memberi keamanan suatu sistem informasi belum terkontrol.

Alasan mengapa perlu dilakukanya Audit tata kelola teknologi informasi pada Politeknik Indonusa Surakarta adalah untuk menilai, memastikan, mengetahui apa penyebabnya serta memberikan rekomendasi terhadap penerapan teknologi informasi yang ada di politeknik indonusa surakarta. Untuk mengevalusi sebuah teknologi informasi harus menggunakan alat bantu berupa framework dan framework yang digunakan adalah COBIT 5, sebab masalah tersebut berkaitan juga dengan area managemen yang terdapat pada framework tersebut.

Penelitian yang menjadi dasar perlu dilaksanakanya penelitian ini antara lain, penelitian Noorhasanah, Wing Wahyu Winarno, Dani Adhipta (2015), dengan judul " Evaluasi Tata Kelola Teknologi Informasi Berbasis Framework COBIT 5".

Penelitian ini menggunakan Framework COBIT 5, merupakan standar yang diakui dan diterima secara internasional, direkomendasikan untuk penerapan tata kelola TI yang baik serta merupakan edisi terbaru dari framework COBIT ISACA (Information System Audit and Control Association) yang menyediakan penjabaran tata kelola TI untuk menggambarkan peran utama dari informasi dan teknologi dalam menciptakan nilai perusahaan. COBIT 5 merupakan sebuah standar tata kelola TI (IT Governance) yang bersifat generik sehingga pengembangannya dapat berbeda-beda untuk setiap organisasi.

Kerangka kerja COBIT (Control Objectives For Information And Related
Technology), dimana model perancangan COBIT lebih bersifat praktis, lebih kuat dalam checklist audit dan cocok untuk monitoring proses TI untuk membantu tercapainya pelaksanaan tata kelola TI yang baik. Sedangkan pada model Peterson dan Weill\&Ross, lebih bersifat teoritis dan model ini sesuai untuk pengaturan atau pembentukan tata kelola TI. Dan untuk model ITGI dan AS 8015 lebih berorientasi pada proses-proses yang harus dilakukan dalam penerapan tata kelola TI. (Putra et al., 2008:19)

COBIT memiliki strukur yang lebih baik dalam hal mengalamatkan masalahmasalah yang berkaitan dengan IT Auditing, dalam hal IT Auditing pada COBIT mencakup area yang lebih luas dan lebih cocok digunakan untuk menilai dan mengevaluasi sebuah IT Governance. Fiturfitur yang dimiliki COBIT dalam penanganan terhadap masalah yang berkaitan dengan manajemen adalah COBIT mampu mereferensikan Critical Success Factor yang dibarengi dengan indikator kinerja dan model kapabilitas sebuah IT Governance. (Simonsson dan Johnson, 2008) berargumen bahwa ITIL tidak mendukung minat dalam IT (Strategic Interest of IT). Dalam hal ini COBIT diakui memiliki struktur IT Goverance yang lebih baik.

Penelitian dengan judul Usulan Model Tata Kelola Teknologi Informasi pada Domain Monitor, Evaluate and Assess dengan Metode Framework COBIT 5 dengan latar belakang masalah yaitu pada saat ini Bank Muamalat memiliki divisi internal audit yang secara langsung bertanggung jawab kepada Direktur Utama. Salah satu tugas dan tanggung jawab Divisi Audit Internal adalah melakukan pemeriksaan berdasarkan rencana audit yeng disusun berdasarkan Risk Based Audit (RBA) dan pedoman audit internal Bank Muamalat. Namun pada divisi Teknologi Informasi sering terjadi keterlambatan waktu dalam setiap tahapan pengerjaan proyek sehingga berpengaruh terhadap schedule berikutnya. (Siti Ida Farida et.al , 2014:2)

\section{b. Rumusan Masalah}

Berdasarkan uraian diatas maka dirumuskan permasalahan yang akan diuraikan solusinya yaitu:

1) Berapa tingkat kemampuan (Capability Level)penerapanTIdengan 
menggunakan Standard Framework COBIT 5 area Manajement Of Enterprise IT domain MEA (Monitor, Evaluate and Assess) pada control objective yaitu MEA01 - Monitor, Evaluate, and Assess Performance and Conformance?

2) Kendala apa saja yang dialami oleh Politeknik Indonusa dalam penerapan TI ?

3) Apa rekomendasi dan saran yang bisa diberikan berkaitan dengan penerapan TI berdasarkan temuan GAP ?

\section{c. Batasan Variabel Penelitian}

Pembatasan yang akan digunakan untuk mempersempit pembahasan adalah sebagai berikut:

1) Pada penelitian ini untuk penyelesaian masalah akan mengacu pada Standard Framework COBIT 5 dengan area Manajement Of Enterprise IT dan lebih difokuskan pada domain MEA (Monitor, Evaluate and Assess) pada control objective yaitu MEA01 - Monitor, Evaluate, and Assess Performance and Conformance.

Alasan mengapa hanya diambil hanya saja pada area Manajemen, karena pada penelitian ini akan diberikan batasan pada kegiatan untuk memantau, mengevaluasi serta memberikan penilaian mengenai penggunaan teknologi informasi. Serta memfokuskan pada pelayanan terhadap pengguna dari sistem informasi.

2) Cakupan tata kelola TI yaitu SIAKAD (Sistem Informasi Akademik), SIMANTA (Sistem Informasi Manajemen Tugas Akhir)

3) Tempat penelitian yang dipilih adalah Politeknik Indonusa Surakarta

\section{d. Tujuan Penelitian}

Tujuan penelitian ini adalah

1) Mengetahuitingkat kemampuan (Capability

Level) penerapan teknologi informasi pada Politeknik Indonusa Surakarta dengan menggunakan Standard Framework COBIT 5 area Manajement Of Enterprise IT domain MEA (Monitor, Evaluate and Assess) pada control objective yaitu MEA01 - Monitor, Evaluate, and Assess Performance and Conformance.

2) Memberikan informasi berkaitan tentang kendala yang dialami oleh Politeknik Indonusa dalam penerapan TI.
3) Memberikan rekomendasi berkaitan kendala yang dialami Politeknik Indonusa dalam penerapan TI.

4) Sebagai salah satu kelulusan jenjang strata 2 Magister Teknik Informatika STMIK AMIKOM Yogyakarta

5) Dapat mengaplikasikan metode COBIT 5 untuk evaluasi TI terutama domai MEA (Monitor, Evaluate and Assess)

e. Manfaat Penelitian Manfaat

dari penelitian ini adalah 1)

Manfaat Ilmiah

Hasil penelitian ini akan memberikan penilaian dan rekomendasi terhadap tata kelola untuk meningkatkan TI Politeknik Indonusa Surakarta dan metode yang digunakan adalah metode COBIT 5.

2) Manfaat bagi penulis

Penelitian ini merupakan pengaplikasian dari ilmu yang diperoleh penulis selama menempuh pendidikan di program pendidikan MTI Universitas AMIKOM Yogyakarta.

3) Manfaat bagi Politeknik Indonusa

Surakarta

Penelitian ini dapat dijadikan acuan bagi Politeknik Indonusa Surakarta dalam meningkatkan kualitas tata kelola TI yang ada saat ini serta untuk meningkatkan efisiensi dan produktifitas dalam rangka memberikan pelayanan yang lebih baik lagi kepada Mahasiswa.

\section{METODE PENELITIAN}

\section{a. Metode Penelitian}

Penelitian ini menggunakan metode Survey Research, merupakan metode penelitian yang bersifat kualitatif. Sampel dari metode ini berasal dari satu populasi dan pengumpulan data menggunakan kuesioner. Pemilihan sampel menggunakan sampel probabilitas, sampel probabilitas yaitu metode pemilihan sampel yang dilakukan secara acak.

\section{b. Metode Pengumpulan Data}

Bagian ini memuat penjelasan secara lengkap dan terinci tentang cara-cara yang digunakan dalam proses pengumpulan data untuk jenis data yang diperlukan. Misalnya melalui observasi, wawancara, eksperimen, atau penyebaran angket. Jika metode penyebaran angket digunakan, maka blangko angket harus dilampirkan dalam proposal Tesis. Untuk setiap metode pengumpulan 
data, harus dijelaskan tentang jenis data yang dikumpulkan dengan metode-metode yang terkait. Bagian ini juga memuat penjelasan secara lengkap dan terinci tentang jenis data yang diperlukan untuk analisis dalam pembahasan.

1) Data primer

Data primer diperoleh dari kuesioner yang diberikan dan di isi oleh responden yang berasal dari populasi yang sudah dipilih.

2) Data sekunder

a) Metode studi pustaka

Penulis mencari sumber pustaka yang relevan dengan penelitian yang dilakukan, serta sumber pustaka yang diambil adalah sumber yang telah memiliki sumber yang bisa diakui keabsahan dari penelitian yang dilakukan sebelumnya.

b) Metode dokumentasi

Penulis mengumpulkan dokumen mulai dari peninputan data serta laporan yang bisa dikeluarkan oleh Aplikasi TI yang ada pada Politeknik Indonusa Surakarta.

\section{c. Alur Penelitian}

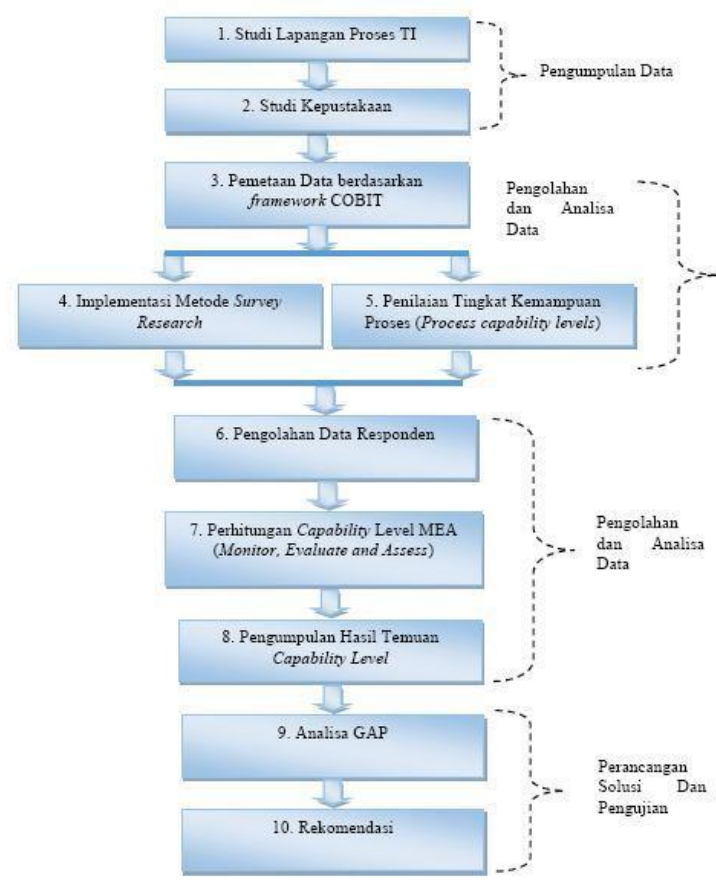

Gambar 1. Alur Penelitian
Penjelasan dari alur diatas :

1. Melakukan studi mengenai jalanya proses penggunaan Teknologi Informasi yang ada pada Politeknik Indonusa Surakarta dengan cara observasi, wawancara.

2. Mencari studi kepustakaan berkaitan dengan audit tata kelola teknologi informasi dengan Jurnal, buku yang berkaitan dengan tatakelola, artikel ilmiah.

3. Memilih domain yang ada pada COBIT 5 yaitu Domain MEA (Monitor, Evaluate and Assess) pada control objective yaitu MEA01 - Monitor, Evaluate, and Assess Performance and Conformance.

4. Mengimplementasikan Metode survey research dan menggabungkan dengan RACI Chart cobit.

5. Penilaian tingkat kemampuan proses (process capability levels) proses penilaian untuk mengetahui tingkat kemampuan proses TI pada Politeknik Indonusa Surakarta.

6. Pengolahan data responden merupakan penghitungan dari proses isian kuesioner yang telah diisi oleh responden.

7. Perhitungan Capability Levels MEA (Monitoring, Evaluate and Assess merupakan langkah untuk memperoleh tingkat kemampuan penggunaan TI saat ini.

8. Pengumpulan hasil temuan Capability Levels merupakan hasil temuan yang diperoleh dari hasil perhitungan pada proses Capability Levels.

9. Analisa GAP

Berdasarkan hasil perhitungan capability level, maka telah diperoleh tingkat kemampuan penggunaan Teknologi Informasi saat ini (current capability) di Politeknik Indonusa Surakarta. Dari hasil pengolahan data sebelumnya, maka sudah didapatkan nilai kemampuan yang diinginkan oleh UTI. Diantara tingkat kemampuan saat ini (as is) dan yang diharapkan (to be)

10. Rekomendasi merupakan usulan untuk aktifitas perbaikan, pemenuhan yang harus dilakukan oleh UTI 


\section{TINJAUAN PUSTAKA a.}

\section{Audit Teknologi Informasi}

Audit pada dasarnya adalah proses sistematis dan obyektif dalam memperoleh dan mengevaluasi bukti-bukti tindakan ekonomi, guna memberikan asersi/pernyataan dan menilai seberapa jauh tindakan ekonomi sudah sesuai dengan kriteria yang berlaku dan mengkomunikasikan hasilnya kepada pihak terkait.

"Systematic, independent and documented process for obtaining audit evidence and evaluating it objectively to determine the extent to which the audit criteria are fulfilled". (Artha, 2011)

\section{b. Tata Kelola Teknologi Informasi}

Karen D. Schwartz mengungkapkan bahwa, Tata kelola sederhananya yaitu bagaimana organisasi menyelaraskan dan menempatkan strategi IT dengan strategi bisnis, memastikan bahwa perusahaan tetap pada jalur untuk mencapai strategi dan tujuan mereka serta menerapkan cara-cara yang baik untuk mengukur kinerja IT. Kerangka kerja tata kelola IT harus menjawab beberapa pertanyaan kunci, seperti bagaimana perusahaan IT berfungsi secara keseluruhan kepada proses bisnis dan investasi.

\section{c. Tentang COBIT (Control Objectives for Information and Relate Technology)}

Menurut Sanyoto Gondodiyoto COBIT

adalah kumpulan dokumentasi untuk tata kelola teknologi informasi yang membantu auditor, pengguna dan manajemen untuk menjembatani gap antara resiko bisnis, kebutuhan kontrol dan masalah teknis teknologi informasi. COBIT sangat berguna bagi auditor karena dapat membantu identifikasi teknologi informasi control issues. COBIT juga bermanfaat bagi para pengguna teknologi informasi karena mendapatkan keyakinan atas kehandalan sistem yang dipakai. Sedangkan untuk manajer COBIT berguna untuk mengambil keputusan investasi dibidang teknologi informasi dan menyusun rencana strategi serta keputusan untuk mesin atau procurement.

\section{d. Proses dalam framework COBIT 5}

Pada COBIT 5 terdapat 2 bagian yaitu governance (EDM) dan management (APO, DSS, BAI, MEA). Cobit 5 dibagi menjadi 5 domain utama dan 37 proses. Berikut adalah 5 domain dan 37 proses COBIT 5 (Nanda Putra Wandita):

Domain MEA (Monitor, Evaluate and Assess) Memberikan solusi oleh pengguna akhir. Domain MEA berkaitan dengan pengiriman aktual dan dukungan layanan yang dibutuhkan, seperti mencakup pelayanan, pengelolaan keamanan, dukungan layanan bagi pengguna, dan manajemen data serta fasilitas operasional. MEA memilki 3 sub domain yaitu MEA01 (Monitor, Evaluate and Assess Performance and Conformance), MEA02 (Monitor, Evaluate and Assess the System of Internal Control), MEA03 (Monitor, Evaluate and Assess Compliance with External Requirements).

\section{e. Domain COBIT 5 MEA}

Fokus domain MEA pada COBIT 5 yaitu pada area manajemen yaitu proses penilaian kebutuhan perusahaan dan sistem yang sedang berjalan masih memenuhi atau tidak, memastikan desain dan kontrol mematuhi regulasi, serta monitoring berkaitan dengan penilaian independen berkaitan efektivitas serta kemampuan untuk memenuhi bisnis objektif oleh penilai independen. Domain MEA terdiri dari 3 control objective, antara lain (ISACA, 2012):

MEA01 - Monitor, Evaluate, and Assess Performance and Conformance

Mengumpulkan, memvalidasi dan mengevaluasi bisnis, IT dan tujuan proses dan metrik. Memantau bahwa proses berkinerja terhadap kinerja dan kesesuaian tujuan dan metrik persetujuan dan memberikan pelaporan yang sistematis dan tepat waktu.

1) MEA01.01 Establish a monitoring approach

Terlibat dengan para pemangku kepentingan untuk membangun dan memelihara pendekatan monitoring untuk menentukan tujuan, ruang lingkup dan metode untuk mengukur solusi bisnis dan pelayanan dan kontribusi terhadap tujuan perusahaan. Mengintegrasikan pendekatan ini dengan sistem manajemen kinerja perusahaan.

2) MEA01.02 Set performance and coformance targets

Bekerja dengan para pemangku kepentingan untuk menentukan, meninjau secara berkala, update dan menyetujui 
kinerja dan kesesuaian target dalam sistem pengukuran kinerja.

3) MEA01.03 Collect and process performance and conformance data

Mengumpulkan dan mengolah data tepat waktu dan akurat sesuai dengan pendekatan perusahaan.

\section{4) MEA01.04 Analyse and report} performance

Berkala meninjau dan melaporkan kinerja terhadap target, menggunakan metode yang menyediakan ringkas all-around pandangan kinerja TI dan cocok dalam sistem pemantauan perusahaan.

5) MEA01.05 Ensure the implementation of corrective actions

Membantu para pemangku kepentingan dalam mengidentifikasi, memulai dan pelacakan tindakan korektif untuk mengatasi anomali.

\section{f. Metode Perhitungan Guttman}

Skala Guttman dikembangkan oleh Louis Guttman. Skala Guttman disebut juga dengan Scalogram atau analisis skala (Scale Analysis). Skala Guttman digunakan untuk memperoleh jawaban dari pertanyaan yang diberikan seperti 'ya' dan 'tidak', 'setuju' dan 'tidak setuju', atau 'yakin' dan 'tidak yakin'. Hasil jawaban yang diperoleh kemudian akan dikonversi ke dalam nilai 0 dan 1 . Jawaban 'tidak' dikonversi ke dalam nilai 0 dan jawaban 'ya' ke dalam nilai 1. Hasil konversi kemudian akan dilakukan normalisasi dengan membagi nilai total dengan jumlah pertanyaan yang ada pada setiap level, kemudian setelah dilakukan normalisasi dilakukan perhitungan rata-rata dengan membagi total nilai jawaban dengan jumlah responden (Fajrin Rizkia Pratiwi Suwarno, 2014)

Tabel 1. Penilaian Kapabilitas

\begin{tabular}{|c|c|l|}
\hline $\begin{array}{c}\text { Rentang } \\
\text { Nilai }\end{array}$ & $\begin{array}{c}\text { Nilai } \\
\text { Kapabilitas }\end{array}$ & $\begin{array}{c}\text { Tingkat } \\
\text { Kapabilitas }\end{array}$ \\
\hline $0-0,50$ & 0,00 & $\begin{array}{l}0 \text { Incomplete } \\
\text { Process }\end{array}$ \\
\hline $0,51-1,50$ & 1,00 & $\begin{array}{l}1 \text { Performed } \\
\text { Process }\end{array}$ \\
\hline $1,51-2,50$ & 2,00 & $\begin{array}{l}2 \text { Managed } \\
\text { Process }\end{array}$ \\
\hline $2,51-3,50$ & 3,00 & $\begin{array}{l}3 \text { Established } \\
\text { Process }\end{array}$ \\
\hline $3,51-4,50$ & 4,00 & $\begin{array}{l}4 \text { Predictable } \\
\text { Process }\end{array}$ \\
\hline $4,51-5,00$ & 5,00 & $\begin{array}{l}5 \text { Optimising } \\
\text { Process }\end{array}$ \\
\hline
\end{tabular}

\section{g. Survey Research}

Penelitian survei termasuk ke dalam penelitian yang bersifat kuantitatif untuk meneliti perilaku suatu individu atau kelompok. Pada umumnya penelitian survei menggunakan kuesioner sebagai alat pengambil data. Penelitian survei adalah penelitian yang mengambil sampel dari satu populasi dan menggunakan kuesioner sebagai alat pengumpulan data yang pokok. Dalam penelitian survei diperlukan jumlah populasi yang cukup besar jika penelitinya menginginkan hasil yang mencerminkan kondisi nyata di lapangan. Metode survei ini sangat popular dan banyak digunakan dalam penelitian sosial dan bisnis karena cepat dan mudah untuk dilaksanakan.

\section{h. Capability Model Framework COBIT 5}

Berikut ini tingkatan Capability Model yang dimiliki sebuah organisasi, antara lain:

1) Level 0 : Incomplete Process

Organisasi pada tahap ini tidak melaksanakan proses proses TI yang seharusnya ada atau belum berhasil mencapai tujuan dari proses TI tersebut.

2) Level $1:$ Performed Process

Organisasi pada tahap ini telah berhasil melaksanakan proses TI dan tujuan proses TI tersebut benar-benar tercapai.

3) Level 2:Managed Process

Organisasi pada tahap ini dalam melaksanakan proses TI dan mencapai tujuannya dilaksanakan secara terkelola dengan baik, sehingga ada penilaian lebih karena pelaksanaan dan pencapaiannya dilakukan dengan pengelolaan yang baik. Pengelolaan berupa proses perencanaan, evaluasi dan penyesuaian untuk ke arah yang lebih baik lagi.

4) Level $3:$ Established Process

Organisasi pada tahap ini memiliki proses-proses TI yang sudah distandarkan dalam lingkup organisasi secara keseluruhan. Artinya sudah memiliki standar proses yang berlaku diseluruh lingkup organisasi tersebut.

5) Level 4 : Predictable Process

Organisasi pada tahap ini telah menjalankan proses TI dalam batasanbatasan yang sudah pasti, misalkan batasan waktu. Batasan ini dihasilkan dari pengukuran yang telah dilakukan pada saat pelaksanaan proses TI tersebut sebelumnya. 
6) Level 5 : Optimizing Process

Pada tahap ini, organisasi telah melakukan inovasi-inovasi dan melakukan perbaikan yang berkelanjutan untuk meningkatkan kemampuannya. (ISACA, 2012)

\section{HASIL DAN PEMBAHASAN}

\section{a. Pemetaan Data Berdasarkan Framework COBIT}

Pada penelitian ini standard framework COBIT 5 yang digunakan pada penilaian pengelolaan teknologi informasi pada Politeknik Indonusa Surakarta yaitu area Manajement Of Enterprise IT dan lebih difokuskan pada domain MEA (Monitor, Evaluate and Assess)_pada control objective yaitu MEA01 - Monitor, Evaluate, and Assess Performance and Conformance.

Alasan mengapa hanya diambil hanya saja pada area Manajemen, karena pada penelitian ini akan diberikan batasan pada kegiatan untuk memantau, mengevaluasi serta memberikan penilaian mengenai penggunaan teknologi informasi. Serta memfokuskan pada pelayanan terhadap pengguna dari sistem informasi.

\section{b. Implementasi Metode Survey Research}

Penelitian survei adalah penelitian yang mengambil sampel dari satu populasi dan menggunakan kuesioner sebagai alat pengumpulan data yang pokok. Untuk sampel dari populasi yang diambil juga disesuaikan dengan RACI Chart MEA01.

Responden untuk membantu memberikan masukan dalam pengisian kuesioner adalah semua pihak di Manajemen yang mendapatkan Informed (Informasi) berdasarkan pemetaan RACI Chart COBIT yaitu bagian
Tabel 2. Daftar Responden

\begin{tabular}{|c|l|c|}
\hline No & \multicolumn{1}{|c|}{ Nama Bagian } & Jumlah \\
\hline 1. & Wakil Direktur & 3 \\
\hline 2. & Kepala Program Studi & 5 \\
\hline 3. & Sekretaris Program Studi & 5 \\
\hline 4. & BAAK & 2 \\
\hline 5. & Unit Teknologi Informasi & 2 \\
\hline 6. & $\begin{array}{l}\text { Unit Penelitian dan } \\
\text { Pengabdian Masyarakat }\end{array}$ & 1 \\
\hline 7. & Unit Penjaminan Mutu & 2 \\
\hline 8. & Humas dan Publikasi Tracer & 2 \\
\hline 9. & $\begin{array}{l}\text { Career Center dan Ju Jumlah } \\
\text { Study }\end{array}$ & 24 \\
\hline 10. & Sarana dan Prasarana \\
\hline \multicolumn{2}{|l|}{} \\
\hline
\end{tabular}

Tahapan pengumpulan data yang dilakukan dalam penelitian ini adalah:

1) Pengambilan data yang dilakukan oleh peneliti ketempat obyek penelitian.

2) Peneliti menjelaskan kepada calon responden yang sudah dipilih sebelumnya mengenai teknik pengisian kuesioner dan jika dalam menjelaskan ada kendala maka responden bisa menanyakan hal tersebut kepada peneliti.

3) Pengumpulan data dilakukan dengan membagikan angket kuesioner secara langsung oleh peneliti.

4) Data primer diperoleh dari hasil pengisian angket kuesioner yang di isi oleh responden.

5) Setelah data didapat proses selanjutnya kemudian analisa data.

Pada penelitian ini penyusunan angket bersifat tertutup (berstruktur), hal ini dilakukan karena responden yang akan membantu dalam pengisian kuesioner memiliki wawasan, pengetahuan dan pengalaman yang berbeda-beda serta untuk menghindari mengenai informasi yang tidak ada hubunganya dengan penilitian yang dilakukan. Dengan menggunakan angket kuesioner tertutup para responden hanya memilih salah satu jawaban yang sudah disajikan dalam angket kuesioner. Penyusunan angket kuesioner menggunakan skala Guttman, tujuan menggunakan skala guttman adalah untuk mengetahuan jawaban yang lebih tegas (konsisten) berkaitan dengan pertanyaan yang diajukan. 


\section{c. Penilaian Tingkat Kemampuan Proses (Process Capability Levels)}

Penilaian tingkat kemampuan proses (process capability levels) merupakan proses penilaian untuk mengetahui tingkat kemampuan proses TI pada politeknik indonusa surakarta. Langkah- langkah yang akan dilakukan yaitu dengan menganalisis data dianalisis menggunakan skala pengukuran Guttman dan Capability Level. Skala Guttman akan digunakan untuk menganalisis jawaban isian dari kuesioner yang telah di isi oleh responden. Dari hasil analisis Guttman kemudian dianalisis kembali menggunakan Capability Level dengan acuan COBIT 5. Langkah-langkah yang akan dilakukan dalam tahapan ini yaitu dengan :

1) Pengambilan data yang dilakukan oleh peneliti ketempat obyek penelitian.

2) Peneliti menjelaskan kepada calon responden yang sudah dipilih sebelumnya mengenai teknik pengisian kuesioner dan jika dalam menjelaskan ada kendala maka responden bisa menanyakan hal tersebut kepada peneliti.

3) Pengumpulan data dilakukan dengan membagikan angket kuesioner secara langsung oleh peneliti.

\section{d. Pengolahan Data Responden}

Pengolahan data responden merupakan tahapan yang akan dilakukan setelah responden yang telah dipilih sebelumnya untuk mengisi kuesioner. Dimana pada tahapan ini akan ditampilkan nilai dari Capability Level dari masing masing responden.

\section{e. Perhitungan Capability Level MEA (Monitor, Evaluate and Assess)}

Perhitungan Capability Level MEA (Monitor, Evaluate and Assess) adalah tahapan setelah mengetahui nilai Capability Level dari masing-masing responden. Kemudian nilai tersebut dibagi rata maka menjadilan nilai Capability Level untuk masing-masing domain.

Hasil perhitungan Capability Level pada domain MEA (Monitor, Evaluate and Assess) proses MEA01.01, MEA01.02, MEA01.03, MEA01.04, MEA01.05 dapat diambil kesimpulan :

1) Nilai Capability Level pada domain MEA (Monitor, Evaluate and Assess) proses baik MEA01.01, MEA01.02, MEA01.03,
MEA01.05 rata-rata 2,7 dan bisa dijelaskan bahwa penggunaan teknologi informasi pada politeknik indonusa surakarta sudah adanya implementasi terhadap teknologi informasi yang ada.

2) Nilai Capability Level pada proses MEA01.01 berada pada level 3 dengan nilai 2.58 .

3) Nilai Capability Level pada proses MEA01.02 berada pada level 3 dengan nilai 2.66 .

4) Nilai Capability Level pada proses MEA01.03 berada pada level 3 dengan nilai 2.64.

5) Nilai Capability Level pada proses MEA01.05 berada pada level 3 dengan nilai 2.91 .

\section{f. Pengumpulan Hasil Temuan Capability} Level

Hasil Temuan Capability Level MEA01.01 Establish A Monitoring Approach

1) Adanya implementasi proses mengidentifikasi pemangku kepentingan (misal manajemen, pemilik proses dan pengguna).

2) Adanya implementasi pada keterlibatan dengan para pemangku kepentingan dan mengkomunikasikan kebutuhan dan tujuan perusahaan untuk menggabungkan monitoring dan reporting menggunakan definisi umum.

3) Adanya implementasi pada proses menyelaraskan dan terus mempertahankan pendekatan monitoring dan evaluasi dengan pendekatan perusahaan dan alat - alat yang akan digunakan untuk pengumpulan dan pelaporan data perusahaan (misalnya aplikasi bisnis intelijen).

4) Adanya implementasi pada proses menyetujui tujuan dan metrik (misalnya kesesuaian, kinerja, nilai, risiko), taksonimi (klasifikasi dan hubungan antara tujuan dan metrik) dan data (bukti) penyimpanan.

5) Adanya implementasi pada proses menyetujui proses pengendalian manajemen siklus hidup dan perubahan untuk pemantauan dan pelaporan. Termasuk peluang perbaikan untuk pelaporan, metrik, pendekatan, baselining dan benchmarking.

6) Adanya implementasi pada proses meminta,memprioritaskandan 
mengalokasikan sumber daya untuk pemantauan (mempertimbangkan kesesuaian, efisiensi, efektivitas dan kerahasiaan).

7) Adanya implementasi pada proses yang secara berkala mengevaluasi pendekatan yang digunakan dan mengidentifikasi pemangku kepentingan baru, persyaratan dan sumber daya.

\section{g. Hasil Temuan Capability Level MEA01.02 Set Performance And Coformance Targets}

1) Adanya implementasi pada proses mendefinisikan dan meninjau tujuan secara berkala tujuan dan metrik dengan para pemangku kepentingan untuk mengidentifikasi setiap item signifikan yang hilang serta menetukan kewajaran target dan toleransi.

2) Adanya implementasi pada proses mengkomunikasikan perubahan yang diusulkan untuk kinerja dan kesesuaian target dan toleransi (berkaitan dengan metrik) dengan pemangku kepentingan.

3) Adanya implementasi pada proses mempublikasikan target perubahan dan toleransi kepada pengguna informasi.

4) Adanya implementasi pada proses mengevaluasi apakah tujuan dan metrik sudah memadai, yaitu spesifik, terukur, dapat dicapai, relevan dan terikat waktu.

h. Hasil Temuan Capability Level MEA01.03 Collect And Process Performance And Conformance Data

1) Adanya implementasi pada pengumpulan data dari proses yang didefinisikan, secara otomatis bila memungkinkan.

2) Adanya implementasi pada proses menilai efisiensi (upaya dalam mengkaitkan dengan pemahaman yang ada) dan kesesuaian (makna dan manfaat) serta memvalidasi integritas (akurasi dan kelengkapan) dari data yang dikumpulkan.

3) Adanya implementasi pada proses menggabungkan data untuk mendukung pengukuran metrik yang disetujui.

4) Adanya implementasi pada proses menyelaraskan penggabungan data dengan pendekatan pelaporan dan tujuan perusahaan.

5) Adanya implementasi pada proses menggunakan alat dan sistem yang sesuai untuk pengolahan format data untuk dianalisis.

i. Hasil Temuan Capability Level MEA01.05 Ensure The Implementation Of Corrective Actions

1) Adanya implementasi pada Peninjauan tanggapan manajemen, opsi dan rekomendasi untuk mengatasi masalah dan penyimpangan yang besar.

2) Adanya implementasi pada proses memastikan bahwa penugasan tanggung jawab untuk tindakan korektif bisa dipertahankan.

3) Adanya implementasi pada pelacakan hasil dari tindakan yang dilakukan.

4) Adanya implementasi pada pelaporan hasil kepada para stakeholder (pemangku kepentingan).

\section{j. Analisa GAP}

Daftar hasil perhitungan GAP Capability Level MEA01.01 Establish A Monitoring Approach

1) Penjadwalan mengenai pengontrolan penggunaan teknologi informasi terhadap fitur, informasi, keakuratan data, ketepatan waktu dalam penyampaian informasi.

2) Perbaikan terhadap sistem yang ada melalui pihak ketiga yang menyebabkan lamanya proses perbaikan sistem.

3) Belum mendokumentasikan berkaitan pelaporan perbaikan belum tersusun secara periodik dan tertata.

Berikut hasil temuan dari GAP Capability Level MEA01.02 Set Performance And Coformance Targets

1) Proses pengevaluasian sistem baik berupa tujuan adanya sistem, spesifikasi perangkat teknologi informasi belum dilakukan dengan maksimal sesuai dengan situasi saat ini.

2) Perubahan informasi dari Teknologi Informasi harus dilakukan secara berkala untuk kualitas informasi yang baik.

3) Perlu adanya catatan performa berkaitan tentang evaluasi target dari matrik.

Berikut hasil temuan dari GAP Capability Level MEA01.03 Collect And Process Performance And Conformance Data 
1) UTI belum bisa maksimal dalam melakukan proses pengumpulan data yang baik dari berbagai unit yang akan menginformasikan mengenai sesuatu informasi untuk ditampilan pada Sistem Informasi.

2) Belum adanya kualitas standar kualitas data.

Berikut hasil temuan dari GAP Capability Level MEA01.05 Ensure The Implementation Of Corrective Actions

1) Pemantauan terhadap permintaan perbaikan harus tetap dijadwalkan agar mempermudah pelayanan terhadap pihak yang membutuhkan.

2) Catatan terhadap proses pelacakan dan perbaikan harus tetap didokumentasikan dengan baik dan disesuaikan dengan format yang telah disepakati.

\section{k. Rekomendasi}

Untuk Rekomendasi MEA01.01 Establish A Monitoring Approach

1) Melakukan proses penjadwalan secara berkala dan dilakukan rutin agar informasi yang akan disampaikan sesuai dengan waktu yang tepat

2) Pembekalan yang lebih mendalam kepada SDM UTI terhadap penguasaan bahasa pemrograman dan jika ada keluhan tidak langsung ke pihak ketiga.

3) Penyusunan pelaporan perbaikan harus dilakukan secara periodik serta tertata.

Untuk Rekomendasi MEA01.02 Set

Performance And Coformance Targets

1) Penjadawalan evaluasi yang dilakukan harus terjadwal dan dilakukan sesuai kesepakatan dengan pihak manajemen.

2) Koordinasi kepada semua pihak agar informasi yang akan disampaikan sesuai dengan waktu yang ditetapkan.

3) Adanya catatan performa berkaitan tentang evaluasi target dan matrik.

Untuk Rekomendasi MEA01.03 Collect And Process Performance And Conformance Data

1) Penyaringan, pengumpulan informasi yang baik harus dilakukan dengan melibatkan semua pihak yang ada di Politeknik Indonusa Surakararta.

2) Pembuatan standar kualitas data untuk Politeknik Indonusa Surakarta.
Untuk Rekomendasi MEA01.05 Ensure

The Implementation Of Corrective Actions

1) Pemantauan secara rutin agar pelayanan yang diberikan bisa baik

2) Melakukan pendokumentasian terhadap perbaikan agar pihak yang mengalami kendala tidak terlalu lama menunggu respon.

\section{KESIMPULAN DAN SARAN}

\section{a. Kesimpulan}

Berdasarkan hasil penelitian dan pembahasan, maka dapat ditarik kesimpulan yaitu:

1) Tingkat kemampuan (Capability Level) penerapan TI

a) Nilai Capability Level pada domain MEA (Monitor, Evaluate and Assess) proses baik MEA01.01, MEA01.02, MEA01.03, MEA01.05 rata-rata 2,7 dan bisa dijelaskan bahwa penggunaan teknologi informasi pada politeknik indonusa surakarta sudah adanya implementasi terhadap teknologi informasi yang ada.

b) Nilai Capability Level pada proses MEA01.01 berada pada level 3 dengan nilai 2.58 yang artinya bahwa sudah adanya implementasi terhadap teknologi informasi pada politeknik indonusa surakarta.

c) Nilai Capability Level pada proses MEA01.02 berada pada level 3 dengan nilai 2.66 yang artinya bahwa sudah adanya implementasi terhadap teknologi informasi pada politeknik indonusa surakarta.

2) Kendala dalam penerapan TI antara lain

a) Penjadwalan mengenai pengontrolan penggunaan teknologi informasi terhadap fitur, informasi, keakuratan data, ketepatan waktu dalam penyampaian informasi.

b) Perbaikan terhadap sistem yang ada melalui pihak ketiga yang menyebabkan lamanya proses perbaikan sistem.

c) Belum mendokumentasikan berkaitan pelaporan perbaikan belum tersusun secara periodik dan tertata.

b) Perbaikan terhadap sistem yang ada melalui pihak ketiga yang menyebabkan lamanya proses perbaikan sistem. 
c) Perbaikan terhadap sistem yang ada melalui pihak ketiga yang menyebabkan lamanya proses perbaikan sistem.

d) Belum mendokumentasikan berkaitan pelaporan perbaikan belum tersusun secara periodik dan tertata.

e) Proses pengevaluasian sistem baik berupa tujuan adanya sistem, spesifikasi perangkat teknologi informasi belum dilakukan dengan maksimal sesuai dengan situasi saat ini.

f) Perubahan informasi dari Teknologi Informasi harus dilakukan secara berkala untuk kualitas informasi yang baik.

3) Rekomendasi yang bisa diberikan berkaitan dengan penggunaan TI

a) Melakukan proses penjadwalan secara berkala dan dilakukan rutin agar informasi yang akan disampaikan sesuai dengan waktu yang tepat

b) Pembekalan yang lebih mendalam kepada SDM UTI terhadap penguasaan bahasa pemrograman dan jika ada keluhan tidak langsung ke pihak ketiga.

c) Penyusunan pelaporan perbaikan harus dilakukan secara periodik serta tertata.

d) Penjadawalan evaluasi yang dilakukan harus terjadwal dan dilakukan sesuai kesepakatan dengan pihak manajemen.

e) Koordinasi kepada semua pihak agar informasi yang akan disampaikan sesuai dengan waktu yang ditetapkan.

f) Adanya catatan performa berkaitan tentang evaluasi target dan matrik.

g) Penyaringan, pengumpulan informasi yang baik harus dilakukan dengan melibatkan semua pihak yang ada di Politeknik Indonusa Surakararta. h) Pembuatan standar kualitas data untuk Politeknik Indonusa Surakarta.

i) Pemantauan secara rutin agar pelayanan yang diberikan bisa baik

j) Melakukan pendokumentasian terhadap perbaikan agar pihak yang mengalami kendala tidak terlalu lama menunggu respon.

\section{b. Saran}

1) Perencanaan, pengevaluasian, pendokumentasian dan pengontrolan terhadap TI perlu dilakukan secara terjadwal dan rutin.

2) Untuk penelitian berikutnya diharapkan mengambil jangkauan Domain yang lebih luas serta disesuaikan dengan permasalahan yang akan dicarikan solusinya.

\section{REFERENSI}

Abdul Kadir \& Terra Ch. Triwahyuni, 2003, Pengenalan Teknologi Informasi. Andi Offset. Yogyakarta

H.M., Jogiyanto, 2005, Sistem Teknologi Informasi, Andi, Jogyakarta

ISACA, 2011, COBIT 5: Process Reference Guide Exposure Draft, USA: ISACA

ISACA, 2012, COBIT 5: Enabling Processes Governance and Management Practices. United States of America: ISACA \& ITGI

ISACA, Process Assessment Model (PAM) Using: COBIT 5. USA, 2013.

ISACA, 2014, Control Objective for Information and Related Technology. Retrieved Agustus 27, 2014, from

ISACA:

http://www.isaca.org/COBIT/Pages/def ault.aspx

IT Governance Institute (ITGI) (2007). COBIT 4.1, IT Governance Institute, United States of America

ITGI, 2014, IT Governance Institute. Retrieved Agustus 27, 2014, from www.itgi.org/About_IT_Governance

MR Rungga Nasution, 2012, A Busines Framework for the Government

Sanyoto Gondodiyoto, 2003, Audit Sistem Informasi : pendekatan COBIT: Mitra Wacana Media 
